\title{
Letter
}

\section{Nonconjugated Hybrid of Carbazole and Fluorene: A Novel Host Material for Highly Efficient Green and Red Phosphorescent OLEDs}

Ken-Tsung Wong, You-Ming Chen, Yu-Ting Lin, Hai-Ching Su, and Chung-chih Wu

Org. Lett., 2005, 7 (24), 5361-5364• DOI: 10.1021/ol051977h • Publication Date (Web): 28 October 2005

Downloaded from http://pubs.acs.org on February 17, 2009

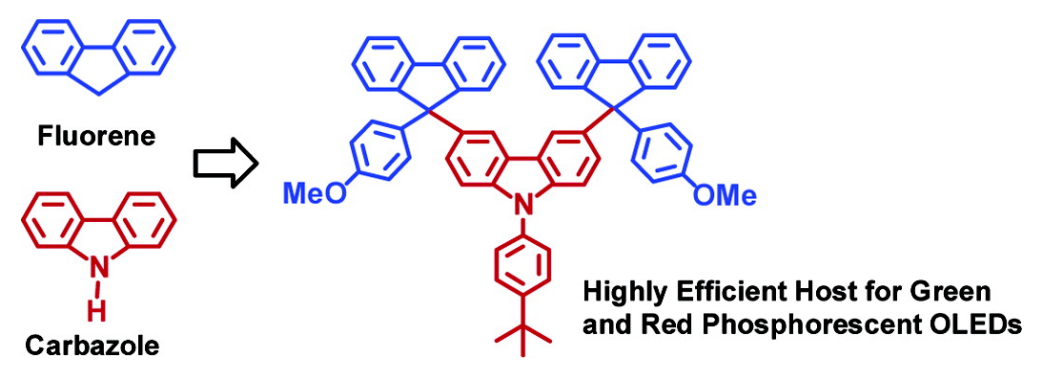

\section{More About This Article}

Additional resources and features associated with this article are available within the HTML version:

- $\quad$ Supporting Information

- Links to the 16 articles that cite this article, as of the time of this article download

- Access to high resolution figures

- $\quad$ Links to articles and content related to this article

- $\quad$ Copyright permission to reproduce figures and/or text from this article

\section{View the Full Text HTML}




\title{
Nonconjugated Hybrid of Carbazole and Fluorene: A Novel Host Material for Highly Efficient Green and Red Phosphorescent OLEDs
}

\author{
Ken-Tsung Wong, ${ }^{\star}, \dagger$ You-Ming Chen, ${ }^{\dagger}$ Yu-Ting Lin, ${ }^{\ddagger}$ Hai-Ching Su, ${ }^{\ddagger}$ and \\ Chung-chih Wu $\mathbf{u}^{*, \neq}$
}

Department of Chemistry and Department of Electrical Engineering, Graduate Institute of Electro-optical Engineering and Graduate Institute of Electronics Engineering, National Taiwan University, Taipei 106, Taiwan

kenwong@ntu.edu.tw

Received August 15, 2005

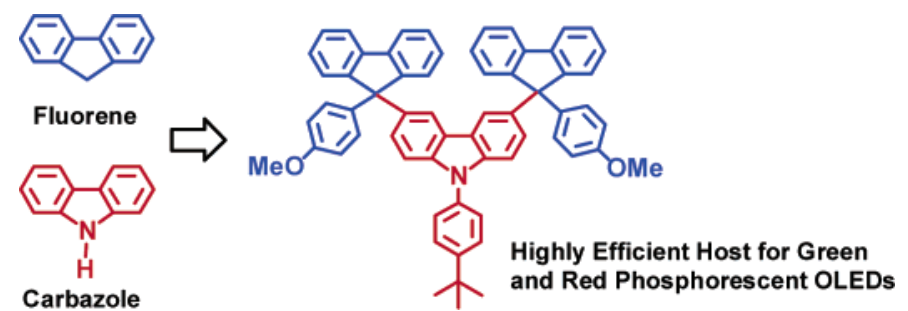

A novel host material for efficient green and red electrophosphorescence devices is obtained by adopting the new molecular strategy of nonconjugated linkage of carbazole and fluorene moieties. The new host combines characteristics of both carbazole and fluorene, giving a large-gap host material suitable for green and red phosphorescent OLEDs. Green and red phosphoresecent OLEDs with external quantum efficiencies up to $10 \%$ have been achieved with this new host material.

Phosphorescent emitters containing transition metals are of substantial interest for highly efficient organic light emitting diodes (OLEDs). ${ }^{1}$ In devices using such materials, both electrogenerated singlet and triplet excitons contribute to the light emission so that emitting devices with $100 \%$ internal quantum efficiency are made possible. ${ }^{2}$ In phosphorescent OLEDs, to reduce quenching associated with relatively long excited-state lifetimes of triplet emitters and triplet-triplet annihilation etc., triplet emitters of heavy-metal complexes are normally used as emitting guests in a host material, and thus effective host materials are of equal importance for efficient phosphorescent OLEDs. The development of effective host materials for triplet emitters imposes some challenges to molecular designs. For preventing reverse energy transfer from the guest back to the host and for

\footnotetext{
$\dagger$ Department of Chemistry.

$\doteqdot$ Department of Electrical Engineering.
}

effectively confining triplet excitons on guest molecules, the triplet level of the host must be larger than that of the triplet

(1) (a) Lamansky, S.; Djurovich, P.; Murphy, D.; Abdel-Razzaq, F.; Lee, H.-E.; Adachi, C.; Burrows, P. E.; Forrest, S. R.; Thompson, M. E. J. Am. Chem. Soc. 2001, 123, 4304. (b) Lu, W.; Mi, B.-X.; Chan, M. C. W.; Hui, Z.; Zhu, N.; Lee, S.-T.; Che, C.-M. Chem. Commun. 2002, 3, 206. (c) Su, Y.-J.; Huang, H.-L.; Li, C.-L.; Chien, C.-H.; Tao, Y.-T.; Chou, P.-T.; Datta, S.; Liu, R.-S. Adv. Mater. 2003, 15, 884. (d) Li, F.; Zhang, M.; Feng, J.; Cheng, G.; Wu, Z.; Ma, Y.; Liu, S.; Sheng, J.; Lee, S. T. Appl. Phys. Lett. 2003, 83, 365. (e) Niu, Y.-H.; Tung, Y.-L.; Chi, Y.; Shu, C.-F.; Kim, J. H.; Chen, B.; Luo, J.; Carty, A. J.; Jen, A. K.-Y. Chem. Mater. 2005, 17, 3532. (f) Zhang, Q.; Zhou, Q.; Cheng, Y.; Wang, L.; Ma, D.; Jing, X.; Wang, F. Adv. Mater. 2004, 16, 432. (g) Adachi, C.; Baldo, M. A.; Forrest, S. R.; Thompson, M. E. Appl. Phys. Lett. 2000, 77, 904. (h) Holmes, R. J.; Forrest, S. R.; Tung, Y.-J.; Kwong, R. C.; Brown, J. J.; Garon, S.; Thompson, M. E. Appl. Phys. Lett. 2003, 82, 2422. (i) Lei, G. T.; Wang, L. D.; Duan, L.; Wang, J. H.; Qiu, Y. Synth. Met. 2004, 144, 249. (j) Tsuboyama, A.; Iwawaki, H.; Furugori, M.; Mukaide, T.; Kamatani, J.; Igawa, S.; Moriyama, T.; Miura, S.; Takiguchi, T.; Okada, S.; Hoshino, M.; Ueno, K. J. Am. Chem. Soc. 2003, 125, 12971.

(2) Adachi, C.; Baldo, M. A.; Thompson, M. E.; Forrest, S. R. J. Appl. Phys. 2001, 90, 5048 
emitter. ${ }^{3}$ Correspondingly, the host materials must have rather large energy gaps. To have a large energy gap, the extent of conjugation in the molecule must be confined, which in turn would usually impose constraints in molecular size. On the other hand, for the molecules to form morphologically stable and uniform amorphous thin films with typical processing techniques, it usually requires the molecules to be bulky and steric. Hence an exquisite and flexible molecular design is highly desired to satisfy these conflicting demands for the host materials of phosphorescent OLEDs.

In this communication, we report a molecular design for large-gap materials adopting the nonconjugated linking of large-gap moieties, such as carbazole and fluorene, that are the usual building blocks for large-gap materials or host materials of phosphorescent devices. ${ }^{3 \mathrm{~b}, 4}$ The nonconjugated hybrid of carbazole and fluorene combines characteristics such as high ambipolar charge carrier mobility of fluorenes ${ }^{5}$ and the low carrier injection barrier of carbazoles, giving rise to a novel host material: difluorene substituted carbazole (DFC) (Scheme 1) with a large triplet energy, a steric and

Scheme 1. Synthesis of the Carbazole-Fluorene Nonconjugated Hybrid DFC
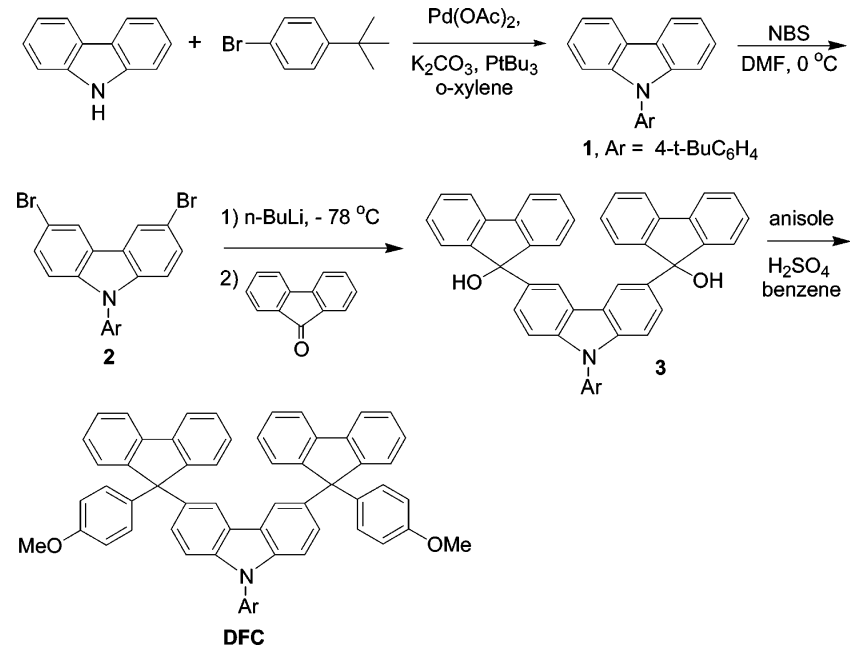

bulky molecular structure, and outstanding thermal and morphological stability. This novel host material is suitable for green to red phosphorescent devices, and highly efficient green and red electrophosphorescent devices have been

(3) (a) Adachi, C.; Kwong, R. C.; Djurovich, P.; Adamovich, V.; Baldo, M. A.; Thompson, M. E.; Forrest, S. R. Appl. Phys. Lett. 2001, 79, 2082. (b) Sudhakar, M.; Djurovich, P. I.; Hogen-Esch, T. E.; Thompson, M. E. J. Am. Chem. Soc. 2003, 125, 7796. (c) Avilov, I.; Marsal, P.; Bredas, J.-L.; Beljonne, D. Adv. Mater. 2004, 16, 1624.

(4) (a) Baldo, M. A.; Lamansky, S.; Burrows, P. E.; Thompson, M. E.; Forrest, S. R. Appl. Phys. Lett. 1999, 75, 4. (b) Holmes, R. J.; Forrest, S R.; Tung, Y.-J.; Kwong, R. C.; Brown, J. J.; Garon, S.; Thompson, M. E. Appl. Phys. Lett. 2003, 82, 2422. (c) Tokito, S.; Iijima, T.; Tsuzuki, T.; Sato, F. Appl. Phys. Lett. 2003, 83, 2459. (d) Yeh, S.-J.; Wu, M.-F.; Chen, C.-T.; Song, Y.-H.; Chi, Y.; Ho, M.-H.; Hsu, S.-F.; Chen, C. H. Adv. Mater. 2005, 17, 285 .

(5) (a) Wu, C.-C.; Liu, T.-L.; Lin, Y.-T.; Hung, W.-Y.; Wong, K.-T.; Chao, T.-C.; Hung, T.-S.; Chen, Y.-M. Appl. Phys. Lett. 2004, 85, 1173. (b) Wu, C.-C.; Liu, T.-L.; Hung, W.-Y.; Lin, Y.-T.; Wong, K.-T.; Chen, R.-T.; Chen, Y.-M.; Chien, Y.-Y. J. Am. Chem. Soc. 2003, 125, 3710. successfully achieved using the titled compound as a host material.

The synthetic pathway of the novel host material DFC through the nonconjugated hybridization of carbazole and fluorene is depicted in Scheme 1. 9-(4-tert-Butylphenyl)carbazole (1) was isolated with a $92 \%$ yield by Pd-catalyzed amination of carbazole and 1-tert-butyl-4-bromobenzene in the presence of a catalytic amount of $\mathrm{Pd}(\mathrm{OAc})_{2}$ and $\mathrm{P}^{t} \mathrm{Bu}_{3}$ in $o$-xylene. Bromination of the cabazole derivative 1 with NBS in DMF at $0{ }^{\circ} \mathrm{C}$ gave 3,6-dibromocarbazole 2 with a yield of $88 \%$. In contrast with the unsuccessful preparation of Grignard reagent of $\mathbf{2}$ for further reactions, the treatment of 3,6-dibromocarbazole 2 with $n$-BuLi at $-78{ }^{\circ} \mathrm{C}$ afforded the dilithiated complex, which was trapped with fluorenone to give diol compound 3 (with a yield of $82 \%$ ). Carbazole and fluorene were thus nonconjugatedly linked. The FriedelCrafts reaction of diol $\mathbf{3}$ with an excess amount of anisole in the presence of sulfuric acid furnished the titled compound DFC with a $56 \%$ yield. It is noteworthy that the flexible molecular design here fully allows one to fine-tune the physical properties of materials by introducing different functional groups through either the 9 position of carbazole or C9 of fluorene.

The electrochemical properties of DFC were probed by cyclic voltammetry (CV). DFC exhibits one reversible oxidation peak at voltage of $0.77 \mathrm{~V}\left(\right.$ versus $\mathrm{Fc} / \mathrm{Fc}^{+}$) and an oxidation onset at $0.69 \mathrm{~V}$, which is similar to that of carbazole derivative $\mathbf{1}$ (with an onset at $0.71 \mathrm{~V}$; see Supporting Information, Figure S-1). Since a single fluorene does not show reversible oxidation, it is therefore rational to attribute the oxidation of the DFC to the oxidation occurring on the central carbazole. The peripheral fluorene moieties nonconjugatedly linked to the carbazole core appear to play an insignificant role on the oxidation potential of the whole molecule, but their addition efficiently blocks the electrochemically active sites (C3 and C6) of carbazole and may give the compound an extra electrochemical stability.

As shown in the optimized molecular structure of DFC calculated with PM3 (Figure 1), linking carbazole and fluorene through the tetrahedral $\mathrm{C} 9$ of fluorene and additional

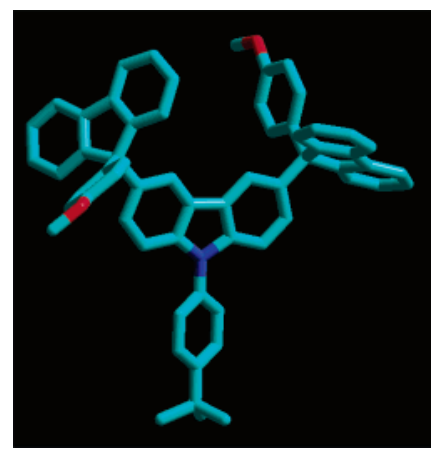

Figure 1. Optimized molecular structure of DFC calculated with PM3. 
aryl substitution on $\mathrm{C} 9$ of fluorene render the molecule rather steric, rigid, and bulky. The rigid linkage through C9 of fluorene is strongly beneficial to the thermal stability of DFC, as indicated by the high decomposition temperature $\left(T_{\mathrm{d}}\right.$, corresponding to $10 \%$ weight loss) of $446{ }^{\circ} \mathrm{C}$ in the thermogravimetric analysis. The steric and bulky molecular conformation also gives the material a rather high glass transition temperature $\left(T_{\mathrm{g}}\right)$ of $180{ }^{\circ} \mathrm{C}$ as determined by differential scanning calorimetry (DSC; see Supporing Information, Figure S-2), which is essential for morphological stability of thin films. Due to the thermal and morphological stability of DFC, thin films of DFC could be prepared by vacuum deposition and vacuum-deposited DFC forms homogeneous and stable amorphous films.

Figure 2 compares the absorption and fluorescence spectra

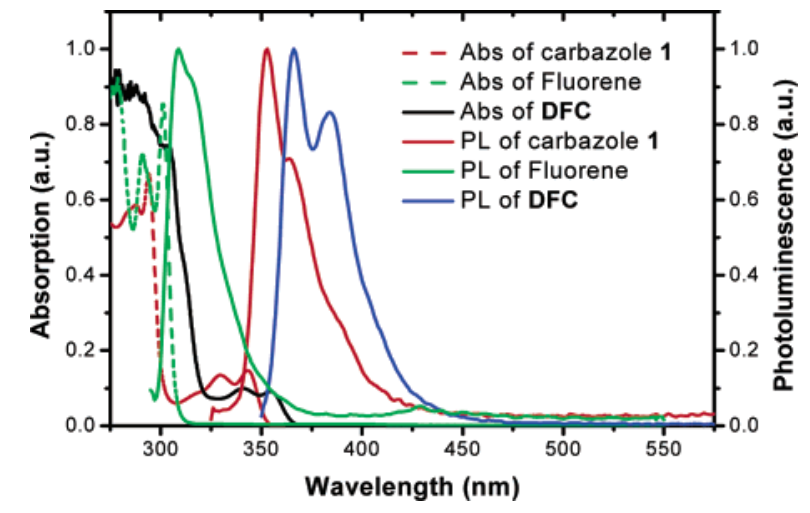

Figure 2. Normalized absorption and fluorescence spectra of carbazole 1, fluorene, and $\mathrm{DFC}$ in $\mathrm{CHCl}_{3}$.

of carbazole 1, fluorene, and $\mathrm{DFC}$ in $\mathrm{CHCl}_{3}$. All three compounds show UV emission in the range of $308-366 \mathrm{~nm}$. A single fluorene shows substantially larger transition energies in either absorption or fluorescence than carbazole 1 and DFC. The features of the lowest absorption band and fluorescence of DFC are very similar to those of carbazole 1, except for a $\sim 15$-nm red shift in both spectra. Such a red shift is similar to that occurring on a carbazole when introducing quarternary substitutions at 3 and 6 positions. ${ }^{6}$ Thus, the lowest absorption band and fluorescence of DFC can be unambiguously attributed mainly to the lowest $\pi-\pi^{*}$ transition of the central carbazole chromophore of DFC. Thus, in terms of absorption and fluorescence of DFC, the tetrahedral C9 carbon of fluorene seemingly serves as a spacer blocking the $\pi$-conjugation of the carbazole core from extending to the peripheral substitution. For evaluating the capability of DFC as a host for electrophosphorescent devices, phosphorescence of DFC in thin films was also detected at $77 \mathrm{~K}$. Figure 3 shows the phosphorescence spectrum of DFC, which exhibits a maximum at $490 \mathrm{~nm}$, corresponding to a triplet energy gap of $2.53 \mathrm{eV}$. Such a

(6) (a) Zhu, Z.; Moore, J. S. J. Org. Chem. 2000, 65, 116. (b) McClenaghan, N. D.; Passalacqua, R.; Loiseau, F.; Campagna, S.; Verheyde, B.; Hameurlaine, A.; Dehaen, W. J. Am. Chem. Soc. 2003, 125, 5356.

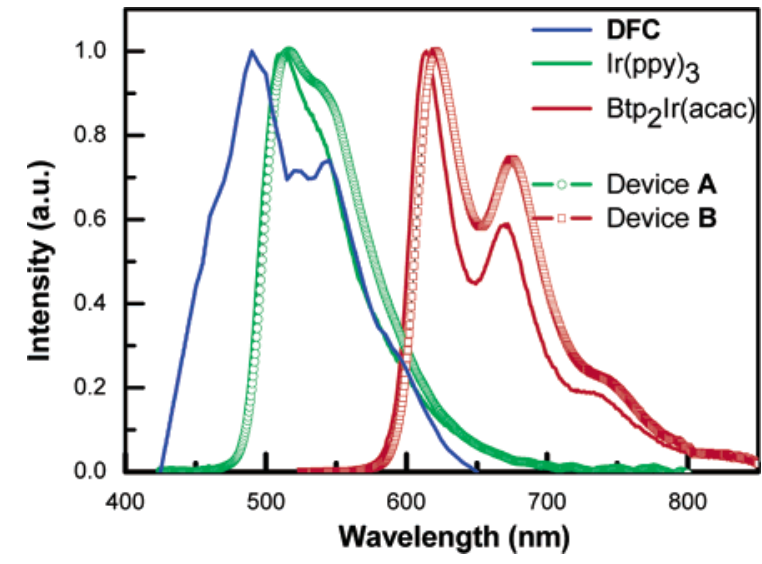

Figure 3. Normalized phosphorescence $(77 \mathrm{~K})$ spectra of DFC in thin films $(\sim 100 \mathrm{~nm})$, the photoluminescence spectra of the green triplet emitter $\operatorname{Ir}(\mathrm{ppy})_{3}$ and the red triplet emitter $\mathrm{Btp}_{2} \operatorname{Ir}(\mathrm{acac})$ in $\mathrm{CHCl}_{3}$ slution, and the electroluminescence spectra of devices $\mathbf{A}$ and $\mathbf{B}$.

triplet energy gap indicates that DFC is suitable as a host material for triplet emitters with emitting wavelength $>490$ $\mathrm{nm}$ or energy gap $<2.53 \mathrm{eV}$ (i.e., green and red). The photophysical data (absorption onset energy) together with electrochemical data (oxidation potential) allow us to estimate the HOMO and LUMO energy levels of DFC to be -5.57 $\mathrm{eV}$ and $-2.20 \mathrm{eV}$ (relative to vacuum level), respectively.

We have investigated the use of DFC as the host material for green and red phosphorescent devices with the device structures of: Device A: ITO/PEDT:PSS $(300 \AA) / T C T A$ $(400 \AA) / 8$ wt \% Ir(ppy) 3 doped in DFC $(200 \AA) / B C P(100$ $\AA) / \mathrm{Alq}_{3}(300 \AA) / \mathrm{LiF}(5 \AA) / \mathrm{Al}$; Device B: ITO/PEDT:PSS $(300 \AA) / T C T A(300 \AA) / 8$ wt \% Btp $2 \operatorname{Ir}(\mathrm{acac})$ doped in DFC $(300 \AA) / \mathrm{BCP}(100 \AA) / \mathrm{Alq}_{3}(600 \AA) / \mathrm{LiF}(5 \AA) / \mathrm{Al}$. The conducting polymer polyetheylene dioxythiophene:polystrene sulfonate (PEDT:PSS) was used as the hole injection layer, $4,4^{\prime}, 4^{\prime \prime}$-tri $(N$-carbazolyl)triphenylamine (TCTA) as the holetransport layer. The emitting layer (EML) consists of the large energy gap DFC doped with 8 wt $\%$ of the common green phosphor $f a c$-tris(2-phenylpyridine)iridium $\left(\operatorname{Ir}(\mathrm{ppy})_{3}\right)$ or red phosphor bis(2-(2'-benzo[4,5- $\alpha]$ thienyl) pyridinato$\left.\mathrm{N}, \mathrm{C}^{3 \prime}\right)\left(\mathrm{Btp}_{2} \operatorname{Ir}(\mathrm{acac})\right) .^{7} \mathrm{~A}$ thin layer of 2,9-dimethyl-4,7diphenyl-1,10-phenanthroline (BCP) was inserted between the EML and the electron-transport tris-(8-hydroxyquinoline)aluminum as the hole-blocking and exciton-blocking layer to provide exciton and carrier confinement. A $5 \AA \mathrm{LiF}$ serves as the electron-injection layer (see Supporting Information, Figure S-3 for device structures and relative HOMOLUMO alignment of active layers).

As shown in Figure 3, the triplet energy of DFC $(\sim 2.53$ $\mathrm{eV})$ is higher than that of $\operatorname{Ir}(\mathrm{ppy})_{3}(\sim 2.42 \mathrm{eV})$ and $\mathrm{Btp}_{2} \mathrm{Ir}-$ (acac) $(\sim 2.0 \mathrm{eV})$, ensuring that the triplet energy transfer from DFC to $\operatorname{Ir}(\text { ppy })_{3}$ or to $B t p_{2} \operatorname{Ir}($ acac $)$ is exothermic and that the transferred triplet excitons are well confined on Ir-

(7) Adachi, C.; Baldo, M. A.; Forrest, S. R.; Lamansky, S.; Thompson, M. E.; Kwong, R. C. Appl. Phys. Lett. 2001, 78, 1622. 


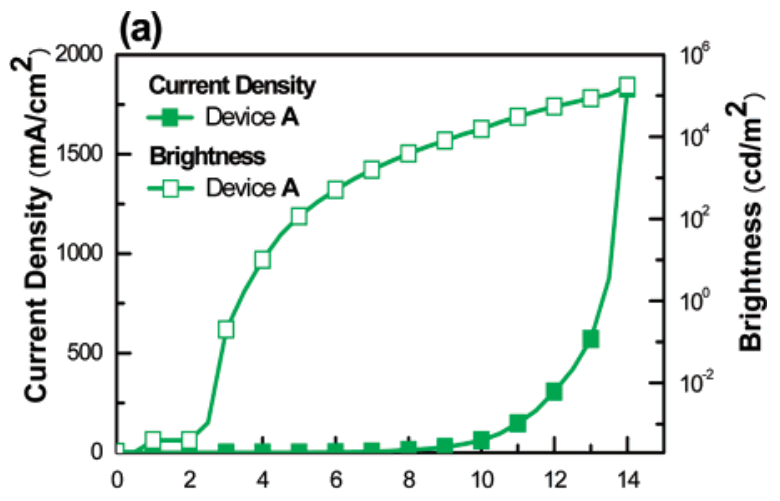

(b) Voltage $(\mathrm{V})$

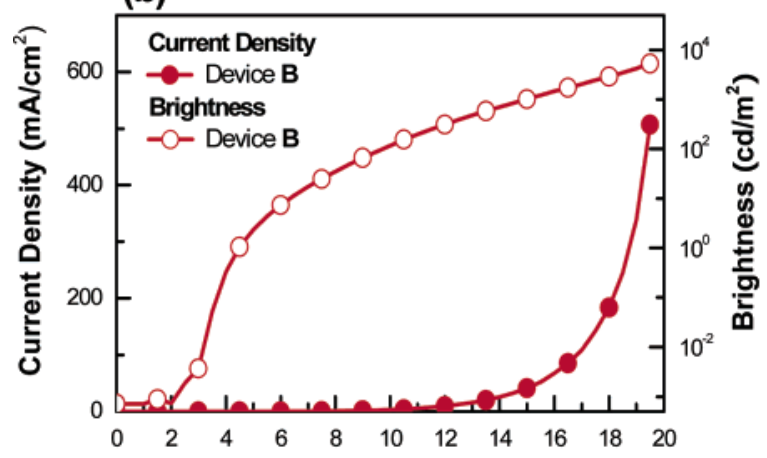

(c)

Voltage $(\mathrm{M}$

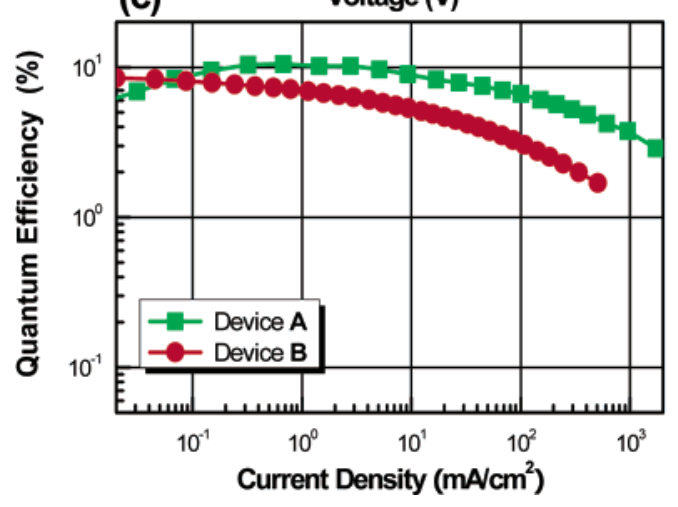

Figure 4. (a) $I-V-L$ characteristics of device $\mathbf{A}$, (b) $I-V-L$ characteristics of device $\mathbf{B}$, (c) EL quantum efficiency as a function of current density for devices $\mathbf{A}$ and $\mathbf{B}$.

(ppy $)_{3}$ or $\mathrm{Btp}_{2} \operatorname{Ir}(\mathrm{acac}){ }^{8}$ As a result, the electrophosphorescence devices $\mathbf{A}$ and $\mathbf{B}$ exhibit pure green $\mathrm{EL}$ from $\operatorname{Ir}(\mathrm{ppy})_{3}$ and pure red EL from Btp 2 Ir(acac) (Figure 3), respectively. Furthermore, no emission from DFC is observed, indicative of complete energy transfer from DFC to the green phosphor or the red phosphor.

Figure 4 shows the current-voltage-brightness and efficiency characteristics of devices $\mathbf{A}$ and $\mathbf{B}$. High brightness of $\sim 176000 \mathrm{~cd} / \mathrm{m}^{2}$ and $\sim 5340 \mathrm{~cd} / \mathrm{m}^{2}$ are obtained for devices $\mathbf{A}$ and $\mathbf{B}$ (Figure 4a,b), respectively. Both devices possess a rather low turn-on voltage of $\sim 2.0-2.5 \mathrm{~V}$ (defined as the voltage at which emission becomes detectable), indicating effective carrier injection into the doped emitting layer from adjacent hole-transporting and hole-blocking layers. The maximal EL quantum efficiencies are $\sim 10.5 \%$ (at $0.5 \mathrm{~mA} / \mathrm{cm}^{2}$ ) for device $\mathbf{A}$ and $\sim 9 \%$ (at $0.01 \mathrm{~mA} / \mathrm{cm}^{2}$ ) for device $\mathbf{B}$ (Figure 4c). The maximal power efficiencies reach $\sim 25 \mathrm{~lm} / \mathrm{W}$ for device $\mathbf{A}$ and $4.0 \mathrm{~lm} / \mathrm{W}$ for device $\mathbf{B}$. Both devices show a gradual decrease in the EL quantum efficiency with current, which is often observed in phosphorescent OLEDs and is usually attributed to triplet-triplet annihilation. ${ }^{9}$ Nevertheless, at a practical brightness of 100 $\mathrm{cd} / \mathrm{m}^{2}$, the EL quantum efficiencies remain above $10 \%$ for device $\mathbf{A}$ and $6.5 \%$ for device $\mathbf{B}$, which are still substantially higher than that of fluorescent green and red OLEDs (3$5 \%$ ) used in current OLED displays. When compared with green or red phosphorescent OLEDs using the same triplet emitter in a common host 4,4'-bis(9-carbazoly)-2,2'-biphenyl (CBP), the devices using DFC as the host show substantially improved performance. For instance, the maximum EL quantum efficiency of device B ( $9 \%)$ obtained here is substantially higher than that obtained with the CBP host $(\sim 7 \%){ }^{7}$ Moreover, these devices also show a less efficient decay at high current densities.

In summary, a novel host material with nonconjugated linkage of carbazole and fluorene moieties has been synthesized and characterized. Green and red electrophosphorescent devices using such a host material show remarkable external quantum efficiencies and less efficiency decay at high current densities.

Acknowledgment. This work was financially supported by the National Science Council of Taiwan.

Supporting Information Available: Details of synthetic procedures and spectroscopic characterization of new compounds, details of device fabrication and characterization, cyclic voltammograms of compound $\mathbf{1}$ and DFC, DSC analysis of DFC, and relative energy levels alignments of active layers of devices $\mathbf{A}$ and $\mathbf{B}$. This material is available free of charge via the Internet at http://pubs.acs.org.

OL051977H

(8) Kawamura, Y.; Goushi, K.; Brooks, J.; Brown, J. J.; Sasabe, H.; Adachi, C. Appl. Phys. Lett. 2005, 86, 071104.

(9) Baldo, M. A.; Adachi, C.; Forrest, S. R. Phys. Rev. B 2000, 62, 10967. 